\title{
Patterns of genetic differention between populations of the specialized herbivore Macrosiphoniella tanacetaria (Homoptera, Aphididae)
}

\author{
B Massonnet ${ }^{1,2}$ and WW Weisser ${ }^{1,2}$ \\ ${ }^{1}$ Zoology Institute, University of Basel, Rheinsprung 9, 4051 Basel, Switzerland; ${ }^{2}$ Institut für Ökologie, Friedrich-Schiller-Universität- \\ Jena, Dornburger Straße 159, 07743 Jena, Germany
}

\begin{abstract}
For herbivorous insects, studies of isolation by distance (IBD) are available for large spatial scales, whereas studies over small geographic distances are relatively rare, in particular for species where population turnover is high. In this study, we investigated IBD and population genetic structure in the aphid Macrosiphoniella tanacetaria, a specialist herbivore of tansy (Tanacetum vulgare). Owing to clonal growth, an individual plant (genet) has one to many shoots (ramets), which can host aphid colonies. Both at the level of ramets and genets, aphid persistence is short, in the order of weeks. Sampling of 17 populations was performed on a logarithmic scale, along the Saale River in Germany in June 2001, with distances between populations ranging from $1 \mathrm{~m}$ to $170 \mathrm{~km}$. For the six microsatellites used, allelic and genotypic variability within aphid populations was high, and
\end{abstract}

deviations from Hardy-Weinberg equilibrium and linkage disequilibrium were frequent. Most pairs of populations were significantly differentiated but there was no pattern of IBD. However, including into the analysis four additional populations from Alsace, France, collected at distances of, on average $470 \mathrm{~km}$, resulted in a weak but significant IBD. Aphids are passive dispersers that are known to occasionally disperse over large distances, even though most dispersal is likely to occur over a small spatial scale. We suggest that for the host-specific $M$. tanacetaria, patterns of genetic variation among populations are, at an ecologically meaningful scale, governed by colonization/extinction dynamics and genetic drift rather than by a drift-dispersal equilibrium.

Heredity (2004) 93, 577-584. doi:10.1038/sj.hdy.6800559

Published online 25 August 2004

Keywords: aphid; specialist; microsatellite; genetic differentiation; Mantel test; isolation by distance

\section{Introduction}

Wright (1943) introduced the isolation by distance (IBD) model to describe the accumulation of local genetic differentiation under geographically restricted dispersal. IBD models (Wright, 1946; Kimura and Weiss, 1964; Maruyama, 1971; Nagylaki, 1976) assume that genetic differentiation at neutral loci will increase with increasing distances between populations due to an equilibrium between genetic drift and dispersal. However, natural populations are often not at such a drift-dispersal equilibrium. Nonequilibrium situations have been shown to emerge, for example, from historical factors, such as recent bottlenecks or range expansion (Lavery et al, 1996; Comes and Abbott, 1998; Latta and Mitton, 1999; Turgeon and Bernatchez, 2001).

Slatkin (1993) proposed a method to test for IBD, by plotting log-transformed $\hat{M}$, an estimator of gene flow, against log-transformed geographical distances between populations. In populations at drift-dispersal equilibrium, a graph of log-transformed $\hat{M}$ against geographical distances would be approximately linear. Absence of any pattern of IBD would suggest that the populations

Correspondence: B Massonnet, Institut für Ökologie, Friedrich-SchillerUniversität-Jena, Dornburger Straße 159, 07743 Jena, Germany.

E-mail: blandine.massonnet@gmx.net

Received 13 January 2003; accepted 21 June 2004; published online 25 August 2004 are far from equilibrium. More recently, Rousset (1997) suggested a similar calculation, based on the regression of $F_{\mathrm{ST}} /\left(1-F_{\mathrm{ST}}\right)$ estimates between pairs of populations on log-transformed geographic distances.

In a review of studies of IBD in phytophagous insects, Peterson and Denno (1998) found that patterns of isolation by distance were found in 24 out of 53 studies. In addition, species mobility had a significant influence on the IBD slope. In moderately mobile species (species that can disperse between 1 and $20 \mathrm{~km}$ ) the slope of the IBD slope was steepest, whereas in highly mobile species $(>20 \mathrm{~km}$ dispersal) and sedentary species $(<1 \mathrm{~km}$ dispersal), the IBD relationship was relatively weak. One recurrent theme of Peterson and Denno (1998) was the scarcity of information on the relationship between isolation by distance and gene flow at a fine spatial scale (ie $0-5 \mathrm{~km})$. In sedentary insect species, gene flow is expected to be predominant over genetic drift at very small spatial scales and less predominant at higher spatial scales. So far, however, few studies have investigated whether there is high gene flow at a very small spatial scale (but see Nève et al, 2000).

Macrosiphoniella tanacetaria (Kaltenbach) is a monophagous aphid feeding on tansy, Tanacetum vulgare (L.) (Heie 1980-1995). The host plant typically grows in wastelands and along streets and rivers (Wagenitz, 1987). Owing to its clonal growth, tansy plants (= genets) consist of one to many shoots (= ramets), each of which can host an aphid colony. Therefore, the habitat of $M$. 
tanacetaria is highly structured and aphids cluster in at least three spatial scales: at the level of ramets, at the level of genets and at the level of sites (Massonnet et al, 2002, 2003). At all these hierarchical levels, persistence of aphids is low with average survival times less than 2 weeks on ramets, less than 4 weeks in genets, and probably only a few years in sites (Massonnet et al, 2002). Most individuals in colonies are wingless, but winged dispersal morphs can occur throughout the season. Colonizations at all spatial levels are common, suggesting $M$. tanacetaria has a metapopulation structure (Massonnet et al, 2002). The scale of dispersal is, however, unclear. While field data suggest that most dispersal is small-scale and plant-to-plant, other aphid species are known to be transported over long distances (Loxdale et al, 1993, but see Loxdale and Brookes, 1990; Hebert et al, 1991; Loxdale et al, 1998). Previous studies on $M$. tanacetaria have shown that, at the beginning of the growing season (i) allelic and genotypic diversities are high, (ii) most aphid populations are not at HardyWeinberg equilibrium, mainly due to heterozygote deficit, and (iii) strong population genetic differentiation exists at a scale of few kilometres (Massonnet et al, 2002, 2003).

In this study, the patterns of genetic differentiation across $M$. tanacetaria populations was investigated following Peterson and Denno's (1998) recommendations: 17 aphid populations were sampled over a large gradient of distances, from $1 \mathrm{~m}$ to $170 \mathrm{~km}$ between aphid populations. We addressed the following questions: (1) are populations in close proximity (distance $<5 \mathrm{~km}$ ) genetically differentiated?; (2) are patterns of isolation by distance visible at a very local scale?; (3) at what spatial scale is the relationship between genetic and geographic distance significant?

\section{Materials and methods}

\section{Population sampling}

Aphid populations were collected from 17 sites located along the Saale River, Germany (Figure 1). In the study area, tansy can be found abundantly on the riverbanks and in wastelands in close proximity to the Saale, but not elsewhere in the relatively narrow $(<5 \mathrm{~km})$ Saale valley. Sampling was performed from the 12-26 June 2001. By this time of the season, aphids have gone through two to three parthenogenetic generations after the emergence of foundresses (fundatrix), from overwintering eggs. As all populations were sampled in a short time period, most collected individuals were probably of the same aphid generation (Dixon, 1998).

From the initial starting population in Jena (population 1, Figure 1), aphid populations were sampled at a logarithmic scale in intervals of 1 to $170000 \mathrm{~m}(170 \mathrm{~km}$, Table 1). For populations at distances of $\leq 100 \mathrm{~m}$ from population one (ie populations 2-6), aphids were sampled from different ramets of the same genet or very close-by genets (Table 1). At larger distances $(>100 \mathrm{~m})$, aphids were collected from ramets of different genets in a given site (Table 1). When fewer than 30 genets occurred at the site (populations 8-10), additional aphids were collected from different ramets within already sampled genets.

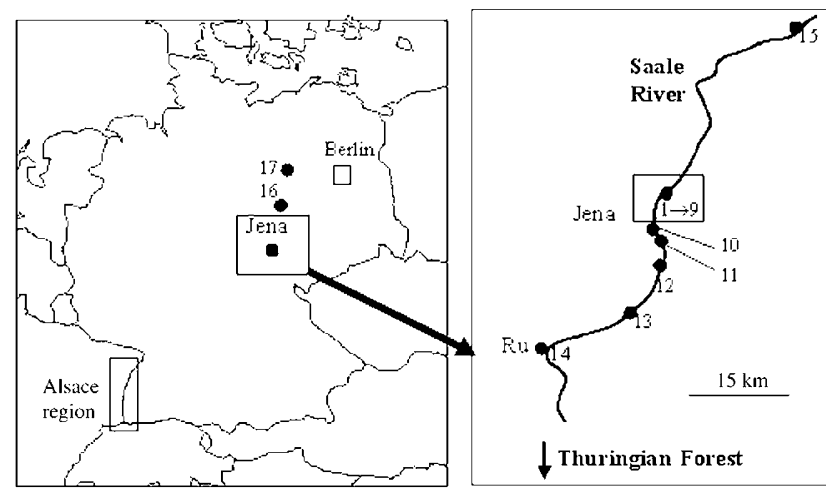

Figure 1 Location of the aphid populations. The 17 aphid populations along the Saale River, Germany, were sampled as follows: sampling started with population 1 and the next populations were sampled further South, until the town of Rudolstadt (Ru) and the local mountain range of the Thuringian Forest (Thüringer Wald). Sampling of the most distant populations (populations 15-17) were located in the North of Jena, also along the Saale River. The four Alsace populations are comprised within the frame on the left-hand side, near to the French-German border.

To test for genetic differentiation at a very large scale, we included four additional aphid populations into the analyses, which were collected for a different study in spring 2001 in the Alsace region, France (Massonnet et al, 2002; Table 1). These populations were located at an average of $470 \mathrm{~km}$ from the Jena populations. Aphids from the Alsace populations were collected as described before, by sampling individuals from all occupied ramets from all genets at a site (Table 1). To test for genetic differentiation at a very large scale, we used the largest data set with the 17 Saale populations and the four Alsace populations. All aphids were kept in $100 \%$ ethanol at $4^{\circ} \mathrm{C}$ until DNA extraction.

\section{Microsatellite analyses}

For the genetic analyses, we aimed at genotyping (i) one adult aphid per ramet from 30 occupied ramets when sampling was performed at the low spatial scale (populations 1-6) and (ii) one adult aphid per genet when sampling was performed at a higher spatial scale (populations 7-17 from the Saale valley and the four Alsace populations). For populations 8-10, there were fewer than 30 genets at the site and adult aphids from additional ramets of these genets were included in the analyses.

In total, DNA from 627 aphids was extracted using the 'salting-out' method of Sunnucks et al (1996). Among the microsatellites developed in this aphid (Massonnet et al, 2001), six polymorphic loci were used for genotyping (Mt2, Mt4, Mt5, Mt6, Mt7 and Mt8). Previously, it has been shown that the resolution of these six loci was sufficient to distinguish most of the genotypes within a population (Massonnet et al, 2002). Microsatellite amplification were performed using a Hybaid thermocycler, on a final volume of $10 \mu \mathrm{l}$ using $0.2 \mu \mathrm{M}$ of each primer, $200 \mu \mathrm{M}$ of each dNTP, $16 \mathrm{mM}\left(\mathrm{NH}_{4}\right)_{2} \mathrm{SO}_{4} ; 67 \mathrm{mM}$ Tris$\mathrm{HCl}, \mathrm{pH} 8.8 ; 0.01 \%$ Tween $20,1.5 \mathrm{mM}$ of $\mathrm{MgCl}_{2}, 0.5 \mathrm{U}$ of DNA Taq polymerase (Genecraft, Münster, Germany) and $1 \mu \mathrm{l}$ of DNA $(5 \mathrm{ng})$. The following amplification program was used for all PCRs: denaturation at $94^{\circ} \mathrm{C}$ for 
Table 1 Details of population sampling and the genetic diversity within the sampled populations

\begin{tabular}{|c|c|c|c|c|c|c|c|c|}
\hline Pop & Location & Sampling date & Distance & No. genets & No. aphids & No. genotype & $\mathrm{D}^{*}$ & $\mathrm{~N}_{a}(S E)$ \\
\hline 1 & Jena patch 1 & 12.06 .01 & 0 & 2 & 30 & 30 & 1.00 & $6.33(1.05)$ \\
\hline 2 & Jena patch 2 & 12.06 .01 & 1 & 2 & 30 & 27 & 0.90 & $5.66(1.20)$ \\
\hline 3 & Jena patch 3 & 12.06 .01 & 4 & 1 & 29 & 28 & 0.96 & $6.00(0.96)$ \\
\hline 4 & Jena patch 4 & 12.06 .01 & 6 & 1 & 30 & 28 & 0.93 & $5.33(1.08)$ \\
\hline 5 & Jena patch 5 & 12.06 .01 & 9 & 1 & 29 & 24 & 0.82 & $4.50(1.14)$ \\
\hline 6 & Jena patch 6 & 12.06.01 & 13 & 3 & 30 & 30 & 1.00 & $5.66(1.30)$ \\
\hline 7 & Jena patch 7 & 12.06 .01 & 90 & 30 & 30 & 29 & 0.96 & 6.00 \\
\hline 8 & Jena patch 8 & 12.06 .01 & 450 & 2 & 30 & 26 & 0.86 & $4.83(0.96)$ \\
\hline 9 & Wöllnitz & 12.06 .01 & 1000 & 21 & 30 & 30 & 1.00 & $5.66(0.66)$ \\
\hline 10 & Am Schloss. & 13.06 .01 & 1800 & 12 & 30 & 27 & 0.90 & $6.33(0.88)$ \\
\hline 11 & Göschwitz & 13.06.01 & 3200 & 30 & 30 & 27 & 0.90 & $5.66(1.35)$ \\
\hline 12 & Rothenstein & 12.06 .01 & 7000 & 30 & 29 & 29 & 1.00 & $4.83(0.65)$ \\
\hline 13 & Grosseuterdorf & 12.06 .01 & 17000 & 30 & 30 & 26 & 0.86 & $6.00(0.93)$ \\
\hline 14 & Rudolstadt & 13.06.01 & 31000 & 30 & 30 & 28 & 0.93 & $5.50(0.84)$ \\
\hline 15 & Namburg & 26.06 .01 & 53000 & 30 & 30 & 23 & 0.76 & $5.00(0.68)$ \\
\hline 16 & Halle & 26.06 .01 & 120000 & 30 & 30 & 28 & 0.93 & $6.00(0.68)$ \\
\hline 17 & Schönfeld & 26.06 .01 & 170000 & 30 & 30 & 26 & 0.86 & $6.66(1.08)$ \\
\hline \multicolumn{9}{|c|}{ Alsace populations } \\
\hline 18 & Breisac & 15.05 .01 & 460000 & 26 & 30 & 20 & 0.66 & $4.60(0.52)$ \\
\hline 19 & Ruis & 16.05 .01 & 462000 & 27 & 30 & 29 & 0.96 & $4.30(0.75)$ \\
\hline 20 & Mulhouse & 17.05.01 & 476000 & 30 & 30 & 29 & 0.96 & $4.20(0.72)$ \\
\hline 21 & Rosenau & 17.05.01 & 482000 & 7 & 30 & 20 & 0.66 & $3.30(0.50)$ \\
\hline
\end{tabular}

For each population: location of aphid populations, sampling date, geographic distance in meters of the population to population 1, number of genets from which the aphids were collected, number of aphids collected, number of different multilocus genotypes found, $D^{*}$ : proportion of number of unique genotypes found per aphid population, $N_{\mathrm{a}}$ : mean number of alleles per locus (standard error).

$2 \mathrm{~min}$, followed by 30 cycles of denaturation at $94^{\circ} \mathrm{C}$ for $20 \mathrm{~s}$, annealing at $60^{\circ} \mathrm{C}$ for $20 \mathrm{~s}$, and elongation at $72^{\circ} \mathrm{C}$ for $30 \mathrm{~s}$, with final extension at $72^{\circ} \mathrm{C}$ for $2 \mathrm{~min}$. [IR-800]and [IR-700]-labelled fragments (MWG-Biotech, München, Germany) were run on a $6 \%$ polyacrylamide gel and detected using a 4200 Licor automated sequencer.

\section{Genetic diversity in $M$. tanacetaria populations}

As $M$. tanacetaria reproduces parthenogenetically most of the time, identical multilocus genotypes in two or more individuals may be due to asexual reproduction. To reduce the effect of clonal reproduction in the analysis, we extracted for each population, out of the original data set (=all aphids genotyped in a population), a data set containing one copy of each multilocus genotype (Sunnucks et al, 1997). This reduced data set (=one copy of each genotype) was used for most analyses (see also Discussion).

For each aphid population, we calculated the proportion of unique genotypes $D^{*}$, as the number of genotypes present only in this population divided by the total number of aphids analysed (Hunter, 1993). Genetic diversity was assessed within each population by calculating, at each of the six loci, the number of alleles, allele frequencies, and expected and observed heterozygosities using GENETIX (Belkhir et al, 1996-1997). Fisher's exact tests were performed at each locus to test for deviations from Hardy-Weinberg equilibrium (HWE) using GENEPOP (Raymond and Rousset, 1995). When HWE was rejected, $U$-tests were used to test heterozygote excess or deficits (HE and HD). Tests for deviations from linkage equilibrium (LD) for pairs of loci within each population were performed using GENEPOP on two data sets: first, with the original data set with all genotyped aphids, and second, with the reduced data set with only one copy of each genotype per population. Levels of significance were adjusted using sequential Bonferroni corrections for all multiple tests (Rice, 1989).

F-statistics (Wright, 1931) were used to analyse within and between population structure. F-statistics were estimated according to Weir and Cockerham (1984) and calculated using FSTAT (Goudet, 1995). Significance of Fstatistics was evaluated using permutation tests included in FSTAT.

\section{Isolation by distance}

The methods and the measures of population differentiation developed by Slatkin $\left(1993\right.$, with $\left.\hat{M}=\left(1 / F_{\mathrm{ST}}-1\right) / 4\right)$ and Rousset $\left(1997\right.$, with $\left.F_{\mathrm{ST}} /\left(1-F_{\mathrm{ST}}\right)\right)$ were used to test for isolation by distance. $F_{\mathrm{ST}}$-values were estimated according to Weir and Cockerham (1984) and all calculations were computed using GENETIX. Mantel (1967) tests were used to test for correlations between matrices of geographic distances and genetic differentiation using GENETIX. In addition, we also performed Mantel tests on a data set that included the four Alsace populations.

\section{Results}

\section{Microsatellite polymorphism}

All six microsatellites were highly polymorphic (Table 1, cf. Massonnet et al, 2002, 2003). More details of the Alsace populations can be found elsewhere (Massonnet et al, 2002 , 2003). In the 17 Saale populations, the number of alleles per locus ranged from seven (Mt4) to 15 (Mt6). In total, 458 multilocus genotypes were found in the 507 aphids analysed (Table 1). Within populations, the mean number of alleles ranged from 4.5 (population 5) to 6.7 (population 15) $($ mean $=5.6)$ (Table 2). The mean number of alleles per population was not correlated with the 
Table 2 For each population, $H_{\text {exp }}$ and $H_{\text {obs: }}$ : expected and observed heterozygosities (standard error), $F_{\text {IS }}$-values and their level of significance, LD: number of pairs of loci in linkage disequilibrium with multiple copies of genotypes (All) and with one copy of each genotype (Ind), HWE: number of loci showing significant deviations from Hardy-Weinberg equilibrium, HE and HD: number of loci showing significant heterozygote excess or deficit (in brackets: number of loci tested for HW, HE and HD)

\begin{tabular}{|c|c|c|c|c|c|c|c|c|}
\hline Pop & $\mathrm{H}_{\text {exp }}$ & $\mathrm{H}_{o b s}$ & $\mathrm{~F}_{I S}$ & $\begin{array}{l}\text { LD } \\
\text { All }\end{array}$ & $\begin{array}{l}\text { Ind } \\
L D\end{array}$ & HWE & $H E$ & $H D$ \\
\hline 1 & $0.63(0.04)$ & $0.56(0.08)$ & $0.126^{* *}$ & 0 & 0 & $0(6)$ & $0(6)$ & $1(6)$ \\
\hline 2 & $0.66(0.05)$ & $0.56(0.07)$ & $0.175^{* * *}$ & 3 & 1 & $1(6)$ & $0(6)$ & $1(6)$ \\
\hline 3 & $0.61(0.05)$ & $0.56(0.09)$ & $0.105^{* *}$ & 0 & 0 & $3(6)$ & $0(6)$ & $3(6)$ \\
\hline 4 & $0.64(0.06)$ & $0.59(0.08)$ & $0.092^{*}$ & 0 & 0 & $1(6)$ & $0(6)$ & $1(6)$ \\
\hline 5 & $0.57(0.04)$ & $0.62(0.12)$ & -0.072 (NS) & 5 & 1 & $0(6)$ & $1(6)$ & $0(6)$ \\
\hline 6 & $0.67(0.05)$ & $0.66(0.06)$ & 0.032 (NS) & 0 & 0 & $0(6)$ & $0(6)$ & $1(6)$ \\
\hline 7 & $0.66(0.05)$ & $0.69(0.06)$ & $-0.022(\mathrm{NS})$ & 0 & 0 & $1(6)$ & $0(6)$ & $0(6)$ \\
\hline 8 & $0.60(0.05)$ & $0.57(0.05)$ & 0.081 (NS) & 3 & 2 & $1(6)$ & $0(6)$ & $1(6)$ \\
\hline 9 & $0.66(0.05)$ & $0.68(0.04)$ & -0.025 (NS) & 0 & 0 & $0(6)$ & $0(6)$ & $0(6)$ \\
\hline 10 & $0.63(0.06)$ & $0.57(0.07)$ & $0.110^{*}$ & 4 & 2 & $0(6)$ & $0(6)$ & $1(6)$ \\
\hline 11 & $0.60(0.08)$ & $0.48(0.09)$ & $0.226^{* * *}$ & 1 & 0 & $2(6)$ & $0(6)$ & $2(6)$ \\
\hline 12 & $0.58(0.06)$ & $0.45(0.06)$ & $0.234^{* * *}$ & 2 & 1 & $3(6)$ & $0(6)$ & $2(6)$ \\
\hline 13 & $0.63(0.05)$ & $0.57(0.07)$ & $0.124^{* *}$ & 6 & 1 & $3(6)$ & $0(6)$ & $2(6)$ \\
\hline 14 & $0.60(0.05)$ & $0.57(0.05)$ & 0.073 (NS) & 0 & 0 & $0(6)$ & $0(6)$ & $0(6)$ \\
\hline 15 & $0.57(0.05)$ & $0.55(0.07)$ & 0.071 (NS) & 4 & 0 & $0(6)$ & $0(6)$ & $0(6)$ \\
\hline 16 & $0.65(0.02)$ & $0.52(0.06)$ & $0.205^{* * *}$ & 2 & 0 & $4(6)$ & $0(6)$ & $3(6)$ \\
\hline 17 & $0.66(0.03)$ & $0.64(0.05)$ & 0.061 (NS) & 2 & 0 & $1(6)$ & $0(6)$ & $1(6)$ \\
\hline
\end{tabular}

NS $P>0.05,{ }^{*} 0.05<P<0.01,{ }^{* *} 0.01<P<0.001,{ }^{* * *} P<0.001$.

number of genets from which individuals were sampled $(N=17, r=0.169, P=0.518)$, nor with the number of different genotypes per population $(N=17, r=0.366$, $P=0.149$ ). The proportion of unique genotypes per population, $D^{*}$, was high and ranged from 0.8 (population 17) to 1.0 (populations $1,6,9,10$ ) (Table 1).

\section{Population genetic structure}

Out of the 102 Fisher's exact tests performed to test deviations from HWE, 20 (16.6\%). were significant (Table 2). Tests of heterozygote excess were significant at one locus only (Mt2, population 5). In contrast, tests for heterozygote deficit were significant at 19 loci (18.6\%) (Table 2). Accordingly, $F_{\text {IS-values were significantly }}$ positive in nine aphid populations (Table 2). Thus, deviations from HWE were essentially due to heterozygote deficit. Using the data set with multiple copies of identical genotypes, there were between zero (in seven populations) and six (in one population) pairs of loci in significant linkage disequilibrium (LD), out of 15 pairwise comparisons (Table 2). Across populations, 10 of the 15 pairs of loci were in significant LD. In the reduced data set with one copy of each genotype, between none (in 11 populations) and two (in 2 populations) pairs of loci were in significant LD. Across populations, three out of the 15 pairs of loci were in significant LD.

\section{Population differentiation}

Tests for population differentiation were based on randomization of genotypes rather than alleles since aphid populations were not at HWE (Goudet et al, 1996). Across all Saale populations, estimates of single locus and multilocus $F_{\mathrm{ST}}$-values were all significantly positive (Table 3).

There was no significant relationship between geographic distances and the different measures of population differentiation for the 17 Saale populations, neither with $\log \hat{M}\left(r=-0.03, P=0.42\right.$, Figure 2a) nor $F_{\mathrm{ST}} /$ $\left(1-F_{\mathrm{ST}}\right)(r=0.05, P=0.58$, Figure $2 \mathrm{~b})$.
Table 3 Estimates of single and multilocus $F_{\mathrm{IS}^{-}}$and $F_{\mathrm{ST}}$-values, across all 17 Saale populations

\begin{tabular}{lcc}
\hline Locus & $\mathrm{F}_{I S}$ & $\mathrm{~F}_{S T}$ \\
\hline Mt2 & $0.032(\mathrm{NS})$ & $0.025^{* * *}$ \\
Mt4 & $0.229^{* * *}$ & $0.012^{* * *}$ \\
Mt5 & $0.194^{* * *}$ & $0.055^{* * *}$ \\
Mt6 & $-0.002(\mathrm{NS})$ & $0.036^{* * *}$ \\
Mt7 & $0.080^{* * *}$ & $0.024^{* * *}$ \\
Mt8 & $0.047(\mathrm{NS})$ & $0.024^{* * *}$ \\
ALL & $0.094^{* * *}$ & $0.030^{* * *}$
\end{tabular}

NS $P>0.05,{ }^{*} 0.05>P>0.01,{ }^{* *} 0.01>P>0.001,{ }^{* * *} P<0.001$.

Additional Mantel tests were performed by successively including more populations into a starting data set of the five closest populations and using $\log \hat{M}$. In all cases, correlation coefficients ranged from 0.2 to -0.167 and did not significantly differ from zero (data not shown). Including the four Alsace populations into the analysis, however, revealed a significant isolation by distance pattern, both for $\log M$-values $(r=-0.42, P=0.006$, Figure 3a) and for $F_{\mathrm{ST}} /\left(1-F_{\mathrm{ST}}\right)$-values $\quad(r=0.52, \quad P=0.003$, Figure $3 b$ )

\section{Discussion}

The main result of this study is that no patterns of isolation by distance were found in the monophagous aphid M. tanacetaria, over a geographic scale of up to $170 \mathrm{~km}$. While all populations were significantly differentiated from one another, a weak but significant correlation between geographic distance and genetic differentiation only emerged when very distant populations were included in the analysis. Below we discuss how these results might be understood in terms of the known population ecology of this species. 
a

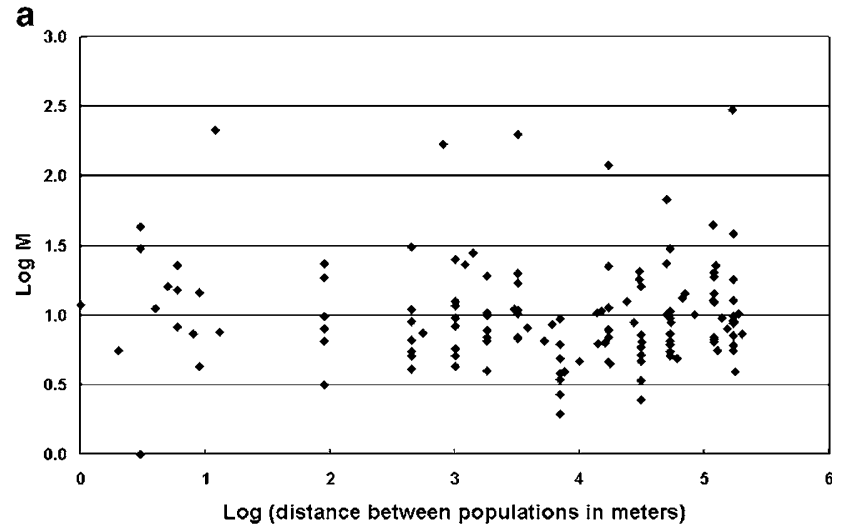

b

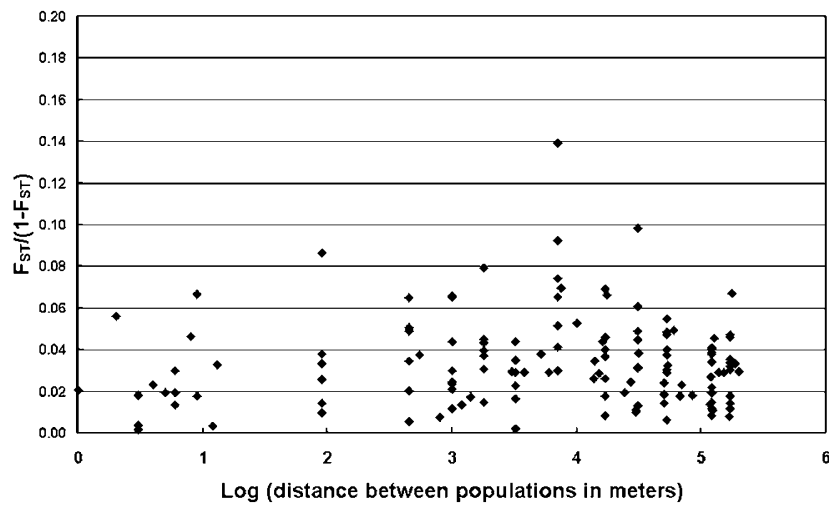

Figure 2 Relationship between the log-transformed geographic distances (in metres) between the 17 aphid populations along the Saale river and (a) log-transformed $\hat{M}$-values, (b) $F_{\mathrm{ST}} /\left(1-F_{\mathrm{ST}}\right)-$ values.

\section{Population ecology of $M$. tanacetaria}

In a previous study, the population dynamics of $M$. tanacetaria were followed on a large number of genets in a number of sites (Massonnet et al, 2002). The study showed that colonization and extinction events were common, both at the level of ramets and genets. At the level of ramets, mean survival was $1.8 \pm 0.1$ weeks and most colonies (63\%) survived for only one week. At the level of genets, mean survival time was $3.6 \pm 0.3$ weeks and aphids persisted on $40 \%$ of the genets for only one week. Maximum persistence time was nine weeks at the level of ramets and 13 weeks at the level of genets, even though aphids were present in the sites for more than six months of the year (Massonnet et al, 2002). Thus within sites, the population ecology of $M$. tanacetaria is characterized by a high turnover at the level of ramets and genets, which is in turn characteristic of metapopulation dynamics. Even though Massonnet et al (2002) did not perform a systematic long-term study, aphids had gone extinct in three out of seven sites that were revisited after a 2-year interval, emphasizing that extinctions at the level of sites are also frequent.

The metapopulation dynamics of $M$. tanacetaria at several spatial levels are likely to influence the genetic composition of the populations. From the field data, it appeared as if ramets and genets were colonized mainly by aphids from nearby plants. Wingless aphids are responsible for most within-genet dispersal but they are a

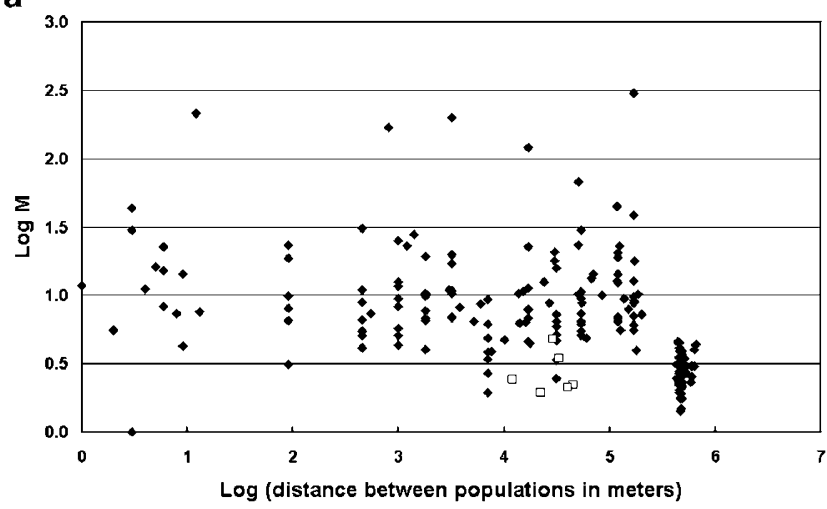

b

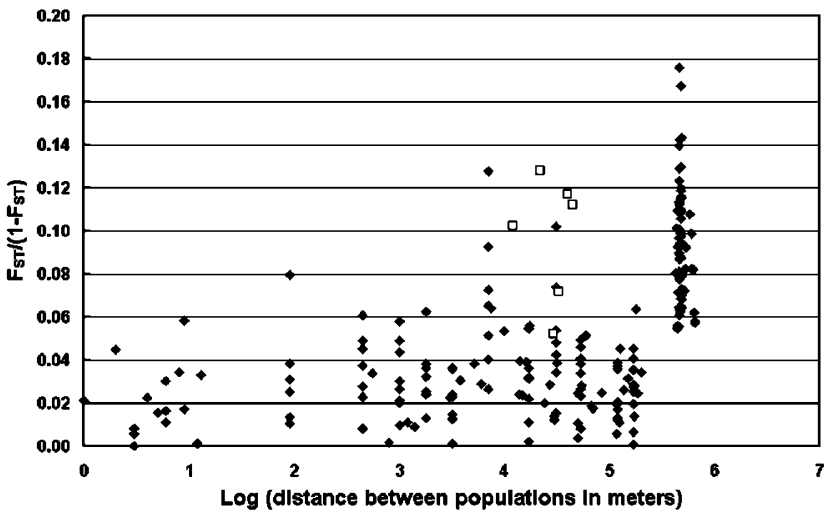

Figure 3 The relationship between the log-transformed geographic distances (in metres) between the 21 aphid populations (Saale valley and Alsace populations) and (a) log-transformed $\hat{M}$-values, (b) $F_{\mathrm{ST}}$ $\left(1-F_{\mathrm{ST}}\right)$-values. The empty squares on all three figures represent the six comparisons between the four Alsace populations.

unlikely to colonize plants more than a few metres away. Thus, genets are generally colonized by winged asexual aphids, found in colonies of M. tanacetaria mainly in the first half of the season (Massonnet et al, 2002). Sites, on the other hand, can only be colonized by winged individuals. The relatively low number of dispersers found in the field study suggests that winged immigrants originate in nearby rather than very distant sites (Massonnet et al, 2002), but from the population ecological data alone the scale of dispersal of these winged indidivuals cannot be deduced. Unfortunately, mark-recapture studies in aphids have limited potential due to large dilution effects (Loxdale et al, 1993). Molecular markers have to be employed to study the scale of aphid dispersal. Most genetic studies of aphids have so far been performed with polyphagous, agriculturally important, pest species and have found high levels of gene flow over large distances and little population differentiation, consistent with the prevailing view of aphids being 'aerial plankton' (eg Loxdale, 1990; Simon and Hebert, 1995; Simon et al, 1999; Llewellyn et al, 2003). However, while aphids are certainly passive dispersers that have been shown to occasionally disperse over large distances, there is evidence that most movements are over a much smaller spatial scale, in particular in host-specific aphids (Loxdale et al, 1993). The best evidence for such restricted movement comes from a limited number of studies also employing molecular 
markers. Restricted gene flow over a small spatial scale has been shown for the blackberry-grain aphid, Sitobion fragariae (Loxdale and Brookes, 1990), for Canadian populations of the Sumac gall aphid, Melaphis rhois (Hebert et al, 1991), for the large raspberry aphid, Amphorophora ideai (Birch et al, 1997), for the damsonhop aphid, Phorodon humuli (Loxdale et al, 1998), and for the gall-inducing Pemphigus spyrothecae (Johnson et al, 2002), although none of the studies was designed to investigate the relationship between geographic and genetic distances. As $M$. tanacetaria is a highly specialized aphid species, our finding that there is significant genetic differentiation between populations at a low spatial scale is consistent with the results of these previous studies.

\section{Population genetics of $M$. tanacetaria}

As aphids reproduce asexually during the season, many individuals of a population have identical genotypes, that is, they are clones (except for rare mutations, see Wilson et al (2003) for a fuller discussion of what constitutes a clone in aphids). In our analysis, we followed the example of other studies and removed all multiple copies of multilocus genotypes for the analysis (cf. Sunnucks et al, 1997). While this procedure avoids low standard errors in estimators and is now common practice for genetic studies of parthenogenetic organisms, there is as yet no theoretical study that investigates the bias caused by reducing the data set. Such work is urgently needed to establish the best method for analysing genetic differentiation in cyclical parthenogenetic organisms. When we used the full data set the analyses yielded identical results (data not shown), but to be consistent with the literature we only reported the results obtained with the reduced data set.

As found in previous studies, spring populations of M. tanacetaria sampled in this study were characterized by high levels of allelic and genotypic diversity (Massonnet et al, 2002, 2003). In addition, most populations of $M$. tanacetaria were not in HWE and heterozygote deficits were often observed (Massonnet et al, 2002, 2003). When using microsatellites, a deficit of heterozygotes may be due to non amplifying alleles (null alleles). In this study, we did not observed any cases of non amplification of microsatellites at any locus. Similarly, in a previous study (Massonnet et al, 2002), a very low proportion $(0.4 \%)$ of all amplifications were unsuccessful. While we cannot rule out that null alleles are present at some loci, it is unlikely that they are the cause for the deficit in heterozygotes. In addition, the distribution of alleles among homo- and heterozygotes does not suggest that some alleles amplify less easily than others (data not shown), which could be another technical reason for an observed deficit in heterozygotes.

A more likely explanation for the significant deficit in heterozygotes is inbreeding, a result of mating between relatives. In $M$. tanacetaria, males are winged whereas females are wingless. As $M$. tanacetaria stops producing winged asexual individuals from the middle of the summer, there is no immigration of individuals into genets except for male dispersal. This restricted dispersal towards the end of the season increases the chances of inbreeding.

\section{Lack of isolation by distance in the Saale valley}

In studies of isolation by distance of phytophagous insects, there has usually been a lack of data at the very small spatial scale (Peterson and Denno, 1998). Sampling at small scales may be of great importance for adequate investigation of patterns of isolation by distance. In our study, we did not find evidence for isolation by distance in M. tanacetaria sampled in the Saale valley, over a scale of up to $170 \mathrm{~km}$. When the four distant Alsace populations were included in the analysis, a weak but significant correlation between geographic and genetic distance emerged, for both measures of genetic differentiation. For the same distance, pairwise comparisons of Alsace populations resulted in higher estimates of population differentiation than comparisons among Saale populations (Figure 3). This is consistent with results from 1999 for seven Alsace populations sampled at a mean distance of $24.2 \mathrm{~km}$ (range $4-35 \mathrm{~km}$ ) where, for instance, pairwise comparisons most often resulted in $F_{\mathrm{ST}}$-values above 0.1 (mean 0.13, Massonnet et al, 2002). This previous study did not find significant IBD, even when two populations in more than $400 \mathrm{~km}$ distance were included, but the total number of populations sampled was low $(N=9)$ and sampling was not designed to test for IBD.

Even though genetic differentiation among Saale populations was not very high, the vast majority of pair-wise comparisons showed significant differentiation. Hutchinson and Templeton (1999) suggested an empirical method to detect nonequilibrium conditions, by contrasting relationships between $F_{\mathrm{ST}}$-values and geographic distances, and by considering the patterns of variance among $F_{\mathrm{ST}}$-values over geographical distances. When there is a recent signal of gene flow (eg after a range expansion), $F_{\mathrm{ST}}$-values should be consistently low over all distances. In contrast, if drift is more dominant (eg after a range fragmentation), $F_{\mathrm{ST}}$-values should be highly variable. Our data appear to be most similar to their third case, where a lack of a regional equilibrium with high variance in $F_{\mathrm{ST}}$-values is interpreted as evidence for strong drift and little gene flow. However, because the method of Hutchinson and Templeton is not quantitative, it is not possible to reject any of the alternative scenarios such as higher gene flow at small distances and drift more important at large distances.

The results from our previous field studies (Massonnet et al, 2002), point, however, to other reasons for the lack of IBD over a small spatial scale. If a population goes extinct, the host plants will be recolonized by one or several dispersers that do not necessarily originate from the nearest populations. Such founder effects are likely to strongly influence the genetic composition of local populations. In addition, random genetic drift becomes more important when population sizes are small (Hedrick, 1999). In the 2001 field survey, aphid colony sizes were often very small. After July, there were generally less than 50 individuals in colonized tansy genets (B Massonnet, unpublished data), which is also reflected in the difficulties in collecting just 30 adult aphids in the sampled populations. Both drift due to small population sizes and founder effects are therefore highly likely to have shaped the patterns of population differentiation observed in this study. 
A significantly positive but weak correlation between genetic and geographic distances was only apparent over a scale of more than $400 \mathrm{~km}$ distance. Thus, while we agree with Peterson (1996) and Peterson and Denno (1998) that it is important to sample populations over a sufficient spatial scale to detect IBD, our results suggest that the detection of IBD over some rather large distance does not necessarily explain processes at an ecologically meaningful smaller spatial scale. As pointed out by Rousset (2001), more emphasis should be put on local processes as patterns of isolation by distance over hundreds of kilometres may be due to processes other than an equilibrium between genetic drift and dispersal. An understanding of the patterns of genetic differentiation between populations clearly requires detailed studies of the relevant processes of dispersal, colonization and drift at the appropriate local scale.

In conclusion, the results of this study suggest that, in $M$. tanacetaria, there is no drift-dispersal equilibrium as envisaged by the IBD model of Wright (1943), over a geographic scale of up to $170 \mathrm{~km}$. We suggest that this is likely to be due to strong founder effects followed by genetic drift in local populations, in a species where colonization and extinction events are frequent. In addition, the cyclic parthenogenetic lifecycle of $M$. tanacetaria with both asexual and sexual (male) dispersal may further complicate matters, and some modelling would be required to analyse the drift-dispersal equilibrium expected under various types of dispersal in organisms with such life-cycles.

\section{Acknowledgements}

We thank Andreas Werries for help with DNA extraction. Jérome Goudet, John J Sloggett and two referees gave valuable comments on previous versions of this paper. This work was supported by Grant No. 3100-053852.98 of the Swiss Nationalfonds.

\section{References}

Belkhir K, Borsa P, Chikhi L, Gouget J, Bonhomme F (19961997). GENETIX 3.07. Available at http:/ / www.univ-montp2. $\mathrm{fr} / \sim$ genetix/genetix.htm.

Birch ANE, Fenton B, Malloch G, Jones AT, Phillips MS, Harower BE et al (1997). Ribosomal spacer length variability in the large raspberry aphid, Amphorophora idaei (Aphidinae: Macrosiphini). Ins Mol Biol 3: 239-245.

Comes HP, Abbott RJ (1998). The relative importance of historical events and gene flow on the population structure of a mediterranean ragwort, Senecio gallicus (Asteraceae). Evolution 52: 355-367.

Dixon AFG (1998). Aphid Ecology, Chapman \& Hall: London.

Goudet J (1995). FSTAT (version 1.2): a computer program to calculate F-statistics. J Hered 86: 485-486.

Goudet J, Raymond M, de Meeüs T, Rousset F (1996). Testing differentiation in diploid populations. Genetics 144: 19331940.

Hebert PDN, Finston TL, Foottit R (1991). Patterns of genetic diversity in the sumac gall aphid Melaphis rhois. Genome 34: 757-762.

Hedrick PW (1999). Genetics of Populations, Jones and Bartlett Publishers: London.

Heie OE (1980-1995). The Aphidoidea of Fennoscandia and Denmark, Parts I-VI. Fauna Entomologica Scandinavica, Klampenborg: Denmark.
Hunter CL (1993). Genotypic variation and clonal structure in coral populations with different disturbance histories. Evolution 47: 1213-1228.

Hutchinson DW, Templeton AR (1999). Correlation of pairwise genetic and geographic distance measures: inferring the relative influences of gene flow and drift on the distribution of genetic diversity. Evolution 53: 1898-1914.

Johnson PCD, Whitfield JA, Foster WA, Amos W (2002). Clonal mixing in the soldier-producing aphid Pemphigus spyrothecae (Hemiptera: Aphididae). Mol Ecol 11: 1525-1531.

Kimura M, Weiss GH (1964). The stepping stone model of population structure and the decrease of genetic correlation with distance. Genetics 49: 561-576.

Latta RG, Mitton JB (1999). Historical separation and present gene flow through a zone of secondary contact in Ponderosa pine. Evolution 53: 769-776.

Lavery S, Moritz C, Fielder DR (1996). Genetic patterns suggest exponential population growth in a declining species. Mol Biol Evol 13: 1106-1113.

Llewellyn M, Loxdale HD, Harrington R, Brookes CP, Clark SJ, Sunnucks P (2003). Migration and genetic structure of the grain aphid (Sitobion avenae) in Britain related to climate and clonal fluctuation as revealed using microsatellites. Mol Ecol 12: $21-34$

Loxdale HD, Brookes CP (1990). Temporal genetic stability within and restricted migration (gene flow) between local populations of the blackberry-grain aphid Sitobion fragariae in south-east England. J Anim Ecol 59: 497-514.

Loxdale HD, Brookes CP, Wynne IL, Clark SJ (1998). Genetic variability within and between english population of the damson-hop aphid, Phorodon humuli (Hemiptera: Aphididae), with special reference to esterases associated with insecticide resistance. Bull Entomol Res 88: 513-526.

Loxdale HD, Hardie J, Halbert S, Foottit R, Kidd NAC, Carter CI (1993). The relative importance of short- and long- range movement of flying aphids. Biol Rev 68: 291-311.

Mantel N (1967). The detection of disease clustering in a generalized regression approach. Cancer Res 27: 209-220.

Maruyama T (1971). Analysis of population structure. II. Twodimensional stepping stone models of finite length and other geographically structured populations. Ann Hum Genet 35: 179-196.

Massonnet B, Leterme N, Simon JC, Weisser WW (2001). Characterization of microsatellite loci in the aphid species Macrosiphoniella tanacetaria (Homoptera, Aphididae). Mol Ecol Notes 1: 14-15.

Massonnet B, Leterme N, Simon JC, Weisser WW (2002). Metapopulation structure of the specialised herbivore Macrosiphoniella tanacetaria (Homoptera, Aphididae). Mol Ecol 11: 2511-2521.

Massonnet B, Leterme N, Simon JC, Weisser WW (2003). Microsatellite analysis of genetic variation within and between three populations of the aphid Macrosiphoniella tanacetaria in the Alsace region, France. In: Simon JC, Dedryer CA, Rispe C, Hullé M (eds) Aphids in a New Millenium, Proceedings of the VI International Symposium on aphids. INRA Editions, pp 253-259.

Nagylaki T (1976). The decay of genetic diversity in geographically structured populations. II. Theor Popul Biol 10: 70-82.

Nève G, Barascud B, Descimon H, Baguette M (2000). Genetic structure of Proclossiana eunomia populations at the regional scale (Lepidoptera, Nymphalidae). Heredity 84: 657-666.

Peterson MA (1996). Long-distance gene flow in the sedentary butterfly, Euphilotes enoptes (Lepidoptera: Lycaenidae). Evolution 50: 1990-1999.

Peterson MA, Denno RF (1998). The influence of dispersal and diet breath on patterns of genetic isolation by distance in polyphagous insects. Am Naturalist 152: 438-446.

Raymond M, Rousset F (1995). GENEPOP (version 1.2): a population genetic software for exact test and eucumenicism. J Hered 86: 248-249. 
Rice WR (1989). Analyzing tables of statistical tests. Evolution 43: 223-225.

Rousset F (1997). Genetic differentiation and estimation of gene flow from $F$-statistics under isolation by distance. Genetics 145: 1219-1228.

Rousset F (2001). Genetic approaches to the estimation of dispersal rates. In: Clobert J, Danchin E, Dhondt AA, Nichols JD (eds) Dispersal, Causes, Consequences and Mechanisms of Dispersal at the Individual, Population and Community Level. Oxford University Press: Oxford, pp 18-28.

Simon JC, Hebert PDN (1995). Patterns of genetic variation among Canadian populations of the bird cherry-oat aphid, Rhopalosiphm padi L. (Homoptera: Aphididae). Heredity 74: 346-353.

Simon JC, Baumann S, Sunnucks P, Hebert PDN, Pierre JS, Le Gallic JF et al (1999). Reproductive mode and population genetic structure of the cereal aphid Sitobion avenae studied using phenotypic and microsatellite markers. Mol Ecol 8: 531-545.

Slatkin M (1993). Isolation by distance in equilibrium and nonequilibrium populations. Evolution 47: 264-279.

Sunnucks P, De Barro PJ, Lushai G, Maclean N, Hales DF (1997) Genetic structure of an aphid studied using microsatellite: cyclic parthenogenesis, differentiated lineages, and host specialization. Mol Ecol 6: 1059-1073.

Sunnucks P, England PR, Taylor AC, Hales DH (1996). Microsatellite and chromosome evolution of parthenogenetic Sitobion aphids in Australia. Genetics 144: 747-756.

Turgeon J, Bernatchez L (2001). Clinal variation at microsatellite loci reveals historical secondary intergradation between glacial races of Coregonus artedi (Teleostei: Coregoninae). Evolution 55: 2274-2286.

Wagenitz G (1987). Illustrierte Flora von Mitteleuropa: Spermatophyta, Band VI, Angiospermae, Dicotyledones 4 Hegi G (ed) Parey, Berlin.

Weir BS, Cockerham CC (1984). Estimating F-statistics for the analysis of population structure. Evolution 38: 1371-1383.

Wilson ACC, Sunnucks P, Hales DF (2003). Heritable genetic variation and potential for adaptive evolution in asexual aphids (Aphidoidea). Biol J Linnean Soc 79: 115-135.

Wright S (1931). Evolution in Mendelian populations. Genetics 16: $97-159$.

Wright S (1943). Isolation by distance. Genetics 28: 114-138.

Wright S (1946). Isolation by distance under diverse systems of mating. Genetics 31: 39-59. 